\title{
EFEKTIVITAS PEMBERIAN TABLET TAMBAH DARAH DAN VITAMIN C TERHADAP KADAR HEMOGLOBIN IBU HAMIL DI WILAYAH KERJA UPT BLUD PUSKESMAS MENINTING
}

\section{EFFECTIVENESS OF TABLET ADDING BLOOD AND VITAMIN C TO HEMOGLOBIN LEVEL OF PREGNANT WOMEN IN WORKING AREA OF UPT BLUD PUSKESMAS MENINTING}

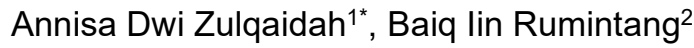

\begin{abstract}
*1Politeknik Kesehatan Mataram, Jln. Prabu Rangkasari, Dasan Cermen, Kelurahan Sandubaya, Mataram, email : annisadwi01ix4@gmail.com, Indonesia

2Politeknik Kesehatan Mataram, Jln. Prabu Rangkasari, Dasan Cermen, Kelurahan Sandubaya, Mataram, email : iinrumintang@gmail.com, Indonesia
\end{abstract}

\begin{abstract}
Background:Based on the results of Basic Health Research in 2013, the prevalence of anemia in pregnant women in Indonesia $37.1 \%$. Prevalence of anemia in pregnant women in the working area of UPT BLUD Meninting Health Center in 2017 amounted to $28.18 \%$. To increase the absorption of hemoglobin levels, iron supplementation needs to be combined with other micronutrients such as vitamin $\mathrm{C}$

Objective:To know the effectiveness of giving tablets added blood and vitamin $C$ to the hemoglobin level of pregnant women

Method:This research used Quasi Experiment with Non Equivalent Control Group design with 30 samples divided into intervention and control group

Results:The characteristics of pregnant women found that most of them were 20-35 years old (83,3\%), high school education $(56,7 \%)$, respondents who did not work or housewives $(96,7 \%)$, respondents multiparas $(70 \%)$, the distance of pregnancy $>5$ years $(61,9 \%)$. The average hemoglobin levels of pregnant women who only get tablets added blood $0.36 \mathrm{gr} / \mathrm{dL}$. The average hemoglobin levels of pregnant women who get tablets added blood and vitamin $\mathrm{C}$ amounted to $1.2 \mathrm{gr} / \mathrm{dL}$. Statistical test results independent $t$ test obtained $\mathrm{p}$ value of 0.006

Conclusion:There is effectiveness of giving tablets added blood and vitamin C to pregnant woman's hemoglobin level
\end{abstract}

Keyword: Tablet Add Blood, Vitamin C, Hemoglobin.

\section{PENDAHULUAN}

Derajat kesehatan masyarakat dipengaruhi oleh 4 faktor utama yaitu lingkungan, perilaku, keturunan, dan pelayanan kesehatan. Indikator utama derajat kesehatan masyarakat dapat dilihat antara lain dari angka kematian, angka kesakitan dan status gizi. Berdasarkan SDKI 2012 angka kematian ibu di Indonesia masih tinggi 359 per 100.000 kelahiran hidup, target
SDGs global 102/100.000 kelahiran hidup pada tahun $2030 .^{1}$

Menurut Saifudin dalam Kunsianah (2015) menyatakan bahwa salah satu penyebab utama kematian ibu baik di dunia maupun negara berkembang secara obstetrik langsung adalah perdarahan (28\%), preeklampsia/eklampsia $(24 \%)$, infeksi $(11 \%)$, trauma obstetri $(5 \%)$ dan lain-lain (11\%). Berdasarkan penyebab terjadinya AKI penyebab utamanya adalah perdarahan 
pasca persalinan atau post partum. Seorang ibu dengan perdarahan hebat akan cepat meninggal jika tidak mendapat perawatan medis yang sesuai, termasuk pemberian obat-obatan, prosedur klinis sederhana, transfusi darah dan operasi. Kondisi tersebut diperburuk apabila ibu mengalami anemia. ${ }^{2}$

Populasi ibu hamil anemia di Indonesia tahun 2013 sebesar 37,1\%, hal ini menunjukkan bahwa angka tersebut mendekati masalah kesehatan masyarakat berat dengan batas prevalensi anemia $\geq 40 \%$. Proporsi anemia ibu hamil di perkotaan $(36,4 \%)$ dan pedesaan $(37,8 \%)$. Riskesdas tahun 2010 dari 80,7\% ibu hamil yang mendapatkan tablet tambah darah hanya $18 \%$ saja yang rutin mengkonsumsi tablet tambah darah selama 90 hari sesuai anjuran, dan meningkat pada tahun 2013 menjadi $33,3 \%$ rutin mengkonsumsi tablet tambah darah selama 90 hari sesuai anjuran dari $89,1 \%$ ibu hamil. ${ }^{3}$

Lombok Barat tahun 2016 tercatat sekitar $12,07 \%$ ibu hamil mengalami anemia, dan pada tahun 2017 meningkat menjadi $15,62 \%$. Angka ini masih tinggi dibandingkan prevalensi anemia di Kota Mataram yaitu sekitar 5,46\%. Prevalensi anemia pada ibu hamil di wilayah kerja UPT BLUD Puskesmas Meninting pada tahun 2016 sebesar 27,01\%. Dan meningkat menjadi $28,18 \%$ pada tahun $2017 .{ }^{4}$

Pemberian tablet besi bersamaan dengan zat gizi mikro lain (multiple micronutrients) lebih efektif dalam meningkatkan status besi dibandingkan dengan hanya memberikan suplementasi besi dalam bentuk dosis tunggal. Oleh karena itu, untuk meningkatkan penyerapan besi di dalam tubuh, suplementasi besi yang diberikan perlu dikombinasi dengan mikronutrien lain seperti vitamin C. Absorbsi zat besi yang efisien dan efektif adalah besi dalam bentuk ferro sebab mudah larut, untuk itu diperlukan suasana asam di lambung dan senyawa yang dapat mengubah ferri menjadi ferro di dalam usus adalah vitamin $\mathrm{C}^{5}$

$$
\text { Mengingat dampak anemia, }
$$
khususnya dapat menurunkan kualitas sumber daya manusia, maka diperlukan suatu metode dalam pemecahan masalah anemia pada ibu hamil salah satunya adalah dengan penambahan vitamin $\mathrm{C}$ dalam mengkonsumsi tablet tambah darah. Dari hasil pengamatan yang dilakukan peneliti di beberapa puskesmas pada bulan Februari 2018, pemberian tablet tambah darah disertai vitamin $C$ belum rutin dilaksanakan karena pengadaan vitamin $C$ yang belum optimal. Data ibu hamil anemia di UPT BLUD Puskesmas Meninting mengalami peningkatan pada tahun 2017. Sehingga berdasarkan uraian latar belakang tersebut, peneliti tertarik untuk melakukan penelitian dengan judul "Efektivitas Pemberian Tablet Tambah Darah dan Vitamin C terhadap Kadar Hemoglobin Ibu Hamil di Wilayah Kerja UPT BLUD Puskesmas Meninting”. 


\section{BAHAN DAN CARA PENELITIAN}

Penelitian ini menggunakan jenis penelitian eksperimen semu atau Quasi Experiment yaitu jenis penelitian yang memiliki kelompok kontrol dan kelompok eksperimen tidak dipilih secara random. Desain penelitian yang digunakan yaitu Non Equivalent Control Group merupakan desain penelitian yang dimungkinkan untuk membandingkan hasil intervensi dengan suatu kelompok kontrol yang serupa, tetapi tidak perlu kelompok yang benar-benar sama. ${ }^{6}$

Penelitian ini telah dilaksanakan pada tanggal 06 Mei 2018 sampai dengan tanggal 07 Juli 2018 di wilayah kerja UPT BLUD Puskesmas Meninting pada semua ibu hamil trimester II dan III yang mengalami anemia maupun tidak anemia yang memenuhi kriteria inklusi. Besar sampel yang digunakan adalah sampel minimal sebanyak 30 responden. Peneliti menggunakan tingkat kemaknaan $p=$ 0,05 dan confidence interval (95\%).

Variabel terikat dalam penelitian ini adalah kadar hemoglobin ibu hamil. Selain itu dikumpulkan pula variabel tentang karakteristik ibu (umur, pendidikan, pekerjaan, paritas, dan jarak kehamilan). Informasi tentang kadar hemoglobin dan variabel-variabel diatas dikumpulkan melalui membaca hasil pemeriksaan hemoglobin yang dilakukan pada saat penelitian dan wawancara terhadap responden. Analisis univariat bertujuan untuk mendeskripsikan karakteristik masing-masing variabel yang diteliti. Sedangkan analisis bivariat bertujuan untuk mengetahui hubungan antar variabel.

\section{HASIL DAN PEMBAHASAN}

Karakteristik ibu hamil adalah jawaban yang diberikan oleh ibu hamil meliputi umur, pendidikan, pekerjaan, paritas, jarak kelahiran yang berhubungan dengan kesehatan ibu.

Telah dilakukan penelitian terhadap 30 ibu hamil yang memenuhi kriteria inklusi, yaitu seluruh ibu hamil yang berada di Poskesdes Bengkaung dan Poskesdes Batulayar - Wilayah Kerja UPT BLUD Puskesmas Meninting yang bersedia menjadi responden penelitian, ibu hamil dengan usia kehamilan trimester II dan III (usia kehamilan 13-32 minggu) dengan kadar hemoglobin <11 $\mathrm{gr} / \mathrm{dl}$ dan kadar hemoglobin $>11 \mathrm{gr} / \mathrm{dl}$, ibu hamil yang mendapatkan tablet tambah darah (TTD).

Distribusi karakteristik ibu hamil dikumpulkan melalui wawancara yang didapatkan hasil sebagian besar responden berumur antara 20-35 tahun yaitu sebanyak 25 responden $(83,3 \%)$, tingkat pendidikan SMA sebanyak 17 responden (56,7\%), tidak bekerja sebanyak 29 responden $(96,7 \%)$, multipara sebanyak 21 reponden (70\%), jarak kehamilan responden $>5$ tahun sebanyak 13 orang $(61,9 \%)$. 
Tabel 1. Distribusi Karakteristik Ibu Hamil di Wilayah Kerja UPT BLUD Puskesmas Meninting.

\begin{tabular}{ccccccc}
\hline & \multicolumn{3}{c}{ Kelompok } & \multirow{2}{*}{ Total } \\
\cline { 2 - 5 } Karakteristik & Intervensi & \multicolumn{2}{c}{ Kontrol } & & \\
\cline { 2 - 6 } & $\mathbf{n}$ & $\%$ & $\mathbf{n}$ & $\%$ & $\mathbf{n}$ & $\%$ \\
\hline Umur & & & & & & \\
\hline$<20$ tahun & 1 & 6,7 & 2 & 13,3 & 3 & 10 \\
$20-35$ tahun & 14 & 93,3 & 11 & 73,4 & 25 & 83,3 \\
$>35$ tahun & 0 & 0 & 2 & 13,3 & 2 & 6,7 \\
\hline Total & 15 & 100 & 15 & 100 & 30 & 100 \\
\hline Pendidikan & & & & & & \\
\hline SD & 1 & 6,7 & 3 & 20 & 4 & 13,3 \\
SMP & 4 & 26,6 & 3 & 20 & 7 & 23,3 \\
SMA & 9 & 60 & 8 & 53,3 & 17 & 56,7 \\
Perguruan & 1 & 6,7 & 1 & 6,7 & 2 & 6,7 \\
Tinggi & & & & & & \\
\hline Total & 15 & 100 & 15 & 100 & 30 & 100
\end{tabular}

Pekerjaan

$\begin{array}{lllllll}\text { Tidak bekerja } & 14 & 93,3 & 15 & 100 & 29 & 96,7\end{array}$

\begin{tabular}{ccccccc} 
Bekerja & 1 & 6,7 & 0 & 0 & 1 & 3,3 \\
\hline Total & 15 & 100 & 15 & 100 & 30 & 100
\end{tabular}

Paritas

\begin{tabular}{ccccccc}
\hline Primipara & 4 & 26,7 & 5 & 33,3 & 9 & 30 \\
Multipara & 11 & 73,3 & 10 & 66,7 & 21 & 70 \\
\hline Total & 15 & 100 & 15 & 100 & 30 & 100 \\
\hline Jarak & & & & & &
\end{tabular}

Kehamilan

\begin{tabular}{ccccccc}
$<2$ Tahun & 0 & 0 & 1 & 10 & 1 & 4,8 \\
2- 5 tahun & 4 & 36,4 & 3 & 30 & 7 & 33,3 \\
$>5$ Tahun & 7 & 63,6 & 6 & 60 & 13 & 61,9 \\
\hline Total & 11 & 100 & 10 & 100 & 21 & 100
\end{tabular}

Sumber: Data Primer 2018.

Semakin tua umur seseorang maka proses perkembangan mentalnya bertambah baik, mudah menyerap apa yang disampaikan dan mau mengikuti anjuran/nasihat yang diberikan untuk kesehatan dirinya. Berdasarkan tabel 1, bahwa sebagian besar umur responden antara 20-35 tahun yaitu sebanyak 25 orang $(83,3 \%), 10$ orang $(13,3 \%)$ dengan kadar hemoglobin normal, dan 15 orang (50\%) mengalami anemia pada pemeriksaan kadar hemoglobin sebelum diberikan perlakuan. Kadar hemoglobin ibu hamil setelah diberikan perlakuan selama 1 bulan didapatkan ada 20 orang $(66,7 \%)$ dengan kadar hemoglobin normal, dan 5 orang $(16,7 \%)$ mengalami anemia. Hal ini menurunkan angka kejadian anemia sebesar $33,3 \%$.

Berdasarkan tabel 1, bahwa responden yang memiliki tingkat pendidikan terbanyak yaitu SMA sebanyak 17 orang $(56,7 \%), 7$ orang $(23,3 \%)$ tidak anemia dan 10 orang $(33,3 \%)$ mengalami anemia pada pemeriksaan kadar hemoglobin sebelum perlakuan. Kadar hemoglobin setelah perlakuan didapatkan 15 orang (50\%) tidak anemia dan 2 orang $(6,7 \%)$ mengalami anemia pada responden dengan pendidikan terakhir SMA. Hal ini lebih rendah dibandingkan pada responden yang memiliki pendidikan terakhir SD yang masih mengalami anemia pada sebelum perlakuan dan setelah perlakuan sebanyak 4 orang $(13,3 \%)$. Sehingga disimpulkan bahwa tingginya tingkat pendidikan menunjukkan bahwa seseorang telah mengetahui, mengerti dan memahami maksud dari pengobatan yang mereka jalani. Sehingga perbedaan tingkat pendidikan mengakibatkan perbedaan pengetahuan yang diperoleh 
responden tentang konsumsi tablet tambah darah saja ataupun tablet tambah darah disertai vitamin C. $^{7}$

Berdasarkan tabel 1, diperoleh ibu hamil yang tidak bekerja (ibu rumah tangga) yaitu 29 orang $(96,7 \%)$. Dari 29 responden tersebut didapatkan 18 orang mengalami anemia $(60 \%)$ dan 11 orang tidak anemia $(36,7 \%)$ pada awal pemeriksaan sebelum dimulainya perlakuan, kemudian pada akhir pemeriksaan setelah 1 bulan mendapatkan perlakuan dengan mengkonsumsi suplemen yang diberikan yaitu tablet tambah darah saja ataupun tablet tambah darah disertai vitamin C didapatkan 23 orang tidak mengalami anemia $(76,7 \%)$, dan 6 orang mengalami anemia (20\%). Responden yang bekerja sebagai pedagang 1 orang $(3,3 \%)$ mengalami anemia hingga akhir pemeriksaan.

Berdasarkan tabel 1, didapatkan responden dengan jumlah paritas terbanyak yaitu multipara sebanyak 21 orang (70\%). Dari 21 responden tersebut didapatkan 14 orang mengalami anemia (46,7\%) dan 7 orang tidak anemia (23,3\%) pada awal pemeriksaan sebelum dimulainya perlakuan, kemudian pada akhir pemeriksaan setelah 1 bulan mendapatkan perlakuan dengan mengkonsumsi suplemen yang diberikan yaitu tablet tambah darah saja ataupun tablet tambah darah disertai vitamin C didapatkan 15 orang tidak mengalami anemia (50\%), dan 6 orang mengalami anemia (20\%).
Responden yang masih mengalami anemia memiliki usia kehamilan trimester II, dimana pada kehamilan trimester II ini terjadinya hemodilusi (pengenceran).

Hemodilusi ini mengalami puncak pada kehamilan 32-34 minggu. Seorang wanita yang sering melahirkan mengalami resiko kehilangan darah di dalam tubuh yang berdampak pada penurunan kadar hemoglobin. ${ }^{8}$

Berdasarkan tabel 1, didapatkan responden yang memiliki jarak kehamilan terbanyak yaitu $>5$ tahun sebanyak 13 orang $(43,3 \%)$. Dari 13 responden tersebut didapatkan 11 orang mengalami anemia $(36,7 \%)$ dan 2 orang tidak anemia (6,7\%) pada awal pemeriksaan sebelum dimulainya perlakuan, kemudian pada akhir pemeriksaan didapatkan 8 orang tidak mengalami anemia $(26,7 \%)$, dan 5 orang mengalami anemia $(16,7 \%)$.

Tabel 2. Distribusi Kejadian Anemia Ibu Hamil Sebelum dan Setelah Perlakuan di Wilayah Kerja UPT BLUD Puskesmas Meninting.

\begin{tabular}{|c|c|c|c|c|c|c|}
\hline \multirow{3}{*}{$\begin{array}{c}\text { Kejadian } \\
\text { Anemia }\end{array}$} & \multicolumn{4}{|c|}{ Kelompok } & \multirow{2}{*}{\multicolumn{2}{|c|}{ Total }} \\
\hline & \multicolumn{2}{|c|}{ Intervensi } & \multicolumn{2}{|c|}{ Kontrol } & & \\
\hline & $\mathbf{n}$ & $\%$ & $n$ & $\%$ & $\mathbf{n}$ & $\%$ \\
\hline \multicolumn{7}{|l|}{$\begin{array}{c}\text { Sebelum } \\
\text { Perlakuan }\end{array}$} \\
\hline $\begin{array}{c}\text { Tidak } \\
\text { Anemia }\end{array}$ & 6 & 40 & 5 & 33,3 & 11 & 36,7 \\
\hline Anemia & 9 & 60 & 10 & 66,7 & 19 & 63,3 \\
\hline Total & 15 & 100 & 15 & 100 & 30 & 100 \\
\hline \multicolumn{7}{|l|}{$\begin{array}{c}\text { Setelah } \\
\text { Perlakuan }\end{array}$} \\
\hline $\begin{array}{c}\text { Tidak } \\
\text { Anemia }\end{array}$ & 12 & 80 & 11 & 73,3 & 23 & 76,7 \\
\hline Anemia & 3 & 20 & 4 & 26,7 & 7 & 23,3 \\
\hline Total & 15 & 100 & 15 & 100 & 30 & 100 \\
\hline
\end{tabular}

Sumber: Data Primer 2018. 
Berdasarkan tabel 2. didapatkan kejadian anemia pada sebelum perlakuan yaitu $63,3 \%$ responden anemia dan $36,7 \%$ responden tidak anemia. Kemudian setelah perlakuan menjadi $23,3 \%$ responden anemia dan $76,7 \%$ responden tidak anemia.

Tabel 3. Distribusi rata-rata kadar hemoglobin ibu hamil sebelum dan setelah mendapatkan tablet tambah darah di Wilayah Kerja UPT BLUD Puskesmas Meninting.

\begin{tabular}{|c|c|c|c|c|c|}
\hline Variabel & $\mathbf{n}$ & Min & Max & Mean & $\begin{array}{c}\text { Mean } \\
\text { Perbeda } \\
\text { an } \\
\end{array}$ \\
\hline $\begin{array}{l}\text { Kadar Hb } \\
\text { Ibu Hamil } \\
\text { Sebelum } \\
\text { Perlakuan }\end{array}$ & 15 & 9,9 & 12,1 & 10,8 & \\
\hline $\begin{array}{l}\text { Kadar Hb } \\
\text { Ibu Hamil } \\
\text { Setelah } \\
\text { Perlakuan }\end{array}$ & 15 & 10,1 & 12,2 & 11,1 & 0,36 \\
\hline
\end{tabular}

Menurut WHO (2000), batas normal hemoglobin pada ibu hamil yaitu 11,0 gr/dL. Kadar hemogolobin yang didapatkan terdapat peningkatan, penurunan, dan kadar hemoglobin yang tetap pada sebelum dan setelah perlakuan. Hal ini disebabkan beberapa faktor yaitu adanya dampak dari konseling yang telah diberikan sebelum perlakuan sehingga responden mengikuti anjuran yang diberikan, kepatuhan responden dalam mengkonsumsi suplemen yang diberikan, tidak adanya recall setiap hari selama 1 bulan.

Berdasarkan tabel 3, bahwa kadar hemoglobin ibu hamil sebelum perlakuan adalah 10,8 $\mathrm{gr} / \mathrm{dL}$ meningkat menjadi 11,1 $\mathrm{gr} / \mathrm{dL}$ setelah perlakuan, dengan rata-rata peningkatan kadar hemoglobin sebesar 0,36 gr/dL. Dari 15 responden masih ada yang mengalami anemia sebanyak 4 orang $(26,7 \%)$. Penyebab kadar $\mathrm{Hb}<11 \mathrm{gr} / \mathrm{dL}$ diantaranya karena tidak patuh mengkonsumsi tablet tambah darah yang diberikan selama 1 bulan. Kondisi ini kemungkinan akan menyebabkan ibu hamil masih ada yang menderita anemia dan mempunyai resiko terjadinya perdarahan pasca persalinan.

Hasil penelitian ini lebih tinggi dari hasil penelitian yang dilakukan oleh Alviani (2012) dengan judul "Pengaruh suplementasi zat besi dengan penambahan vitamin $C$ terhadap kenaikan kadar $\mathrm{Hb}$ pada ibu hamil trimester III" bahwa rata-rata peningkatan kadar $\mathrm{Hb}$ pada kelompok yang diberikan tablet tambah darah saja adalah 0,2 gr/dL, selama 90 hari ( 3 bulan) dengan selisih 0,16 $\mathrm{gr} / \mathrm{dL}$. Hal ini karena adanya perbedaan lama intervensi. $^{9}$

Distribusi rata-rata kadar hemoglobin ibu hamil sebelum dan setelah mendapatkan tablet tambah darah dan vitamin $C$ yaitu 10,7 $\mathrm{gr} / \mathrm{dL}$, dengan nilai minimum 9,1 gr/dL dan nilai maksimum $12,7 \mathrm{gr} / \mathrm{dL}$. Sedangkan ratarata kadar hemoglobin ibu hamil setelah perlakuan yaitu $11,9 \mathrm{gr} / \mathrm{dL}$, dengan nilai minimum 10,2 gr/dL dan nilai maksimum 13 gr/dL.Rata-rata perbedaan kadar hemoglobin ibu hamil sebelum dan setelah perlakuan yaitu $1,2 \mathrm{gr} / \mathrm{dL}$. 
Tabel 4. Distribusi rata-rata kadar hemoglobin ibu hamil sebelum dan setelah mendapatkan tablet tambah darah dan vitamin C di Wilayah Kerja UPT BLUD Puskesmas Meninting.

\begin{tabular}{lccccc}
\hline Variabel & $\mathbf{n}$ & Min & Max & $\begin{array}{c}\text { Mean } \\
\text { Pean } \\
\text { an }\end{array}$ \\
\hline $\begin{array}{l}\text { Kadar Hb } \\
\text { lbu Hamil }\end{array}$ & 15 & 9,1 & 12,7 & 10,7 & \\
$\begin{array}{l}\text { Sebelum } \\
\begin{array}{l}\text { Perlakuan } \\
\text { Kadar Hb }\end{array}\end{array}$ & & & & 1,2 \\
$\begin{array}{l}\text { lbu Hamil } \\
\text { Setelah } \\
\text { Perlakuan }\end{array}$ & 15 & 10,2 & 13 & 11,9 & \\
$\begin{array}{l}\text { Sumber: Data Primer 2018. } \\
\text { Sumbeda }\end{array}$ & & \\
\end{tabular}

Pemberian tablet tambah darah pada ibu hamil yang disertai vitamin $\mathrm{C}$ lebih baik daripada pemberian tablet tambah darah saja, dimana vitamin $\mathrm{C}$ berfungsi dalam penyerapan besi non hem dengan merubah bentuk ferri menjadi ferro yang dapat meningkatkan penyerapan zat besi (tablet tambah darah) yang dikonsumsi ibu hamil. Vitamin C yang diberikan pada kelompok intervensi ini adalah vitamin $\mathrm{C}$ dengan dosis $100 \mathrm{mg}$, dimana kebutuhan harian normal vitamin C $70 \mathrm{mg} /$ hari.

Hasil penelitian ini lebih tinggi dari hasil penelitian yang dilakukan oleh Didik Hariyadi (2015) yang berjudul "Efektivitas vitamin $\mathrm{C}$ terhadap kadar $\mathrm{Hb}$ pada ibu hamil di Kecamatan Pontianak Timur" bahwa ratarata peningkatan kadar hemoglobin pada kelompok yang diberikan tablet tambah darah dan vitamin $\mathrm{C}$ adalah $1,09 \mathrm{gr} / \mathrm{dL}$ untuk pemberian selama 30 hari (1 bulan) dengan selisih $0,11 \mathrm{gr} / \mathrm{dL} .{ }^{10}$

Analisis efektivitas pemberian tablet tambah darah dan vitamin $C$ terhadap kadar hemoglobin ibu hamil di Wilayah Kerja UPT BLUD Puskesmas Meninting dengan menggunakan uji independent $t$ test terdapat dalam tabel berikut :

Tabel 5. Analisis Efektivitas Pemberian Tablet Tambah Darah dan Vitamin C Terhadap Kadar Hemoglobin Ibu Hamil di Wilayah Kerja UPT BLUD Puskesmas Meninting.

\begin{tabular}{|c|c|c|c|c|c|}
\hline Variabel & $n$ & Mean & SD & SE & $\begin{array}{c}p \\
\text { value }\end{array}$ \\
\hline $\begin{array}{l}\text { Kadar Hb } \\
\text { lbu Hamil } \\
\text { pada } \\
\text { Kelompok }\end{array}$ & 15 & 11,9 & $\begin{array}{l}0,85 \\
289\end{array}$ & $\begin{array}{l}0,22 \\
022\end{array}$ & \\
\hline $\begin{array}{l}\text { Intervensi } \\
\text { Kadar Hb } \\
\text { Ibu Hamil } \\
\text { pada } \\
\text { Kelompok } \\
\text { Kontrol }\end{array}$ & 15 & 11,1 & $\begin{array}{l}0,61 \\
280\end{array}$ & $\begin{array}{l}0,15 \\
822\end{array}$ & 0,006 \\
\hline
\end{tabular}

Berdasarkan tabel 5. diperoleh ratarata kadar hemoglobin ibu hamil pada kelompok intervensi adalah 11,9 $\mathrm{gr} / \mathrm{dL}$ dengan standar deviasi 0,85289 , sedangkan rata-rata kadar hemoglobin ibu hamil pada kelompok kontrol adalah 11,1 gr/dL dengan standar deviasi 0,61280. Hasil uji statistik menggunakan uji independent t-test dengan tingkat kepercayaan 95\% didapatkan $p$ value $=0,006$. Terdapat perbedaan yang signifikan antara kedua kelompok perlakuan ini bahwa pemberian tablet tambah darah disertai dengan vitamin $\mathrm{C}$ lebih efektif dalam meningkatkan kadar hemoglobin ibu hamil dibandingkan dengan memberikan suplementasi tablet tambah darah dalam bentuk dosis tunggal.

Dalam kedua kelompok perlakuan masih terdapat ibu hamil anemia, hal ini juga 
dapat disebabkan oleh karakteristik responden yang tidak homogen. Terdapat responden dengan kehamilan trimester II dan III, dimana pada usia kehamilan tersebut beresiko terjadinya anemia fisiologis.

Dalam Pedoman Penatalaksanaan Pemberian Tablet Tambah Darah Kemenkes RI (2015) untuk meningkatkan penyerapan zat besi sebaiknya tablet tambah darah dikonsumsi bersamaan dengan buah-buahan sumber vitamin C (jeruk, papaya, mangga, jambu biji dan lain-lain) dan jika memungkinkan dengan daging, ikan, atau unggas sehingga penyerapan zat besi dari tablet tambah darah dapat lebih baik. ${ }^{11}$

Hal ini sejalan dengan penelitian Susilo Wirawan (2015) tentang Pengaruh Pemberian Tablet Besi dan Tablet Besi Plus Vitamin C terhadap Kadar Hemoglobin Ibu Hamil, didapatkan hasil yang signifikan pada selisih kadar hemoglobin kedua kelompok perlakuan $(p$ value $=0,001) .{ }^{12}$

\section{KESIMPULAN}

Berdasarkan karakteristik ibu hamil didapatkan bahwa sebagian besar berumur 20-35 tahun $83,3 \%$, pendidikan SMA $56,7 \%$, responden yang tidak bekerja 96,7\%, responden dengan multipara $70 \%$, jarak kehamilan terbanyak yaitu $>5$ tahun sebesar $61,9 \%$.

Rata-rata kadar hemoglobin ibu hamil yang hanya mendapatkan tablet tambah darah pada awal pemeriksaan yaitu 10,8 $\mathrm{gr} / \mathrm{dL}$ meningkat menjadi $11,1 \mathrm{gr} / \mathrm{dL}$ dengan perbedaan rata-rata kadar hemoglobin ibu hamil sebesar 0,36 gr/dL.

Rata-rata kadar hemoglobin ibu hamil yang mendapatkan tablet tambah darah dan vitamin C pada awal pemeriksaan yaitu 10,7 $\mathrm{gr} / \mathrm{dL}$ meningkat menjadi $11,9 \mathrm{gr} / \mathrm{dL}$ dengan perbedaan rata-rata kadar hemoglobin ibu hamil sebesar $1,2 \mathrm{gr} / \mathrm{dL}$.

Terdapat efektivitas pemberian tablet tambah darah dan vitamin C terhadap kadar hemoglobin ibu hamil di wilayah kerja UPT BLUD Puskesmas Meninting Tahun 2018 dengan $p$ value $=0,006$.

\section{TERIMA KASIH}

1. H. Awan Dramawan, S.Pd.,M.Kes., Direktur Politeknik Kesehatan Kemenkes Mataram, (0370) 62138, email: poltekkes.mataram@yahoo.co.id

2. Rosmayadi, SKM.,M.PH., Pimpinan UPT BLUD Puskesmas Meninting, email: pkmmenintingbatulayar@gmail.com

3. Syajaratuddur Faiqah, S.Si.T.,M.Kes., Ketua Jurusan Kebidanan Politeknik Kesehatan Kemenkes Mataram, email: faiqahsyajaratuddur@gmail.com

4. Baiq lin Rumintang, SST.,M.Keb., Pembimbing utama dalam penelitian ini, email: iinrumintang@gmail.com

\section{KEPUSTAKAAN}

1. Dinas Kesehatan Provinsi NTB. Profil Kesehatan Provinsi NTB 2014. NTB: Dikes Provinsi NTB. 2015.

2. Kunsianah. Hubungan Anemia Saat Hamil Dengan Kejadian Perdarahan 
Postpartum di Wilayah Kerja Puskesmas Gemuh 01 Kecamatan Gemuh Kabupaten Kendal. 2014.

3. Riskesdas. Riset Kesehatan Dasar. Jakarta : Kementerian Kesehatan Republik Indonesia. 2013.

4. Dinas Kesehatan Kabupaten Lombok Barat. Laporan PemantauanWilayah Setempat Kesehatan Ibu dan Anak Lombok Barat Tahun 2017. Lombok Barat: Dikes Kabupaten Lombok Barat. 2017.

5. Kementerian Kesehatan RI. Pedoman Penatalaksanaan Pemberian Tablet Tambah Darah. Jakarta: Kemenkes RI. 2015.

6. Notoatmodjo, S. Metodologi Penelitian Kesehatan. Jakarta: Rineka Cipta. 2014.

7. Sulistiyanti, A. Hubungan Tingkat Pengetahuan Ibu Hamil tentang Anemia dengan Kepatuhan Konsumsi Tablet Fe di Wilayah Kerja Puskesmas Masaran 1 Sragen. 2015.

8. Manuaba, Ida Bagus Gede. IImu Kebidanan, Penyakit Kandungan, dan Keluarga Berencana. Jakarta : EGC. 2010.

9. Alviani. Pengaruh Suplementasi Zat Besi Dengan Penambahan Vitamin C Terhadap Kenaikan Kadar Hb Pada Ibu Hamil Trimester III. UNS Digital Library. 2012.

10. Hariyadi, Didik.dkk. Efektivitas Vitamin C Terhadap Kenaikan Kadar HB Pada Ibu Hamil di Kecamatan Pontianak Timur. Poltekkes Kemenkes Pontianak : Jurnal Vokasi Kesehatan. 2015.

11. Kementerian Kesehatan RI. Pedoman Penatalaksanaan Pemberian Tablet Tambah Darah. Jakarta: Kemenkes RI. 2015.

12. Wirawan, Susilo. dkk. Pengaruh Pemberian Tablet Besi dan Tablet Besi Plus Vitamin C Terhadap Kadar Hemoglobin Ibu Hamil. 2015. 